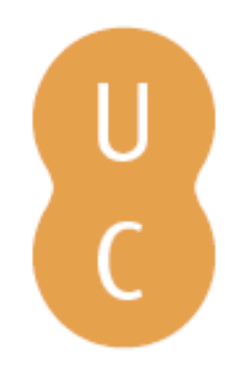

\title{
nombalina
}

\section{A bayesian assessment of unexplained fracture as a forensic test of child ab use: quantification of uncertainty using the Error Odds approach}

\author{
Autor(es): $\quad$ Freeman, M. D. \\ Publicado por: Imprensa da Universidade de Coimbra; International Academy of Legal \\ URL \\ persistente: URI:http://hdl.handle.net/10316.2/31790 \\ DOI: $\quad$ DOI:http://dx.doi.org/10.14195/978-989-26-0173-1_32 \\ Accessed : $\quad$ 26-Apr-2023 08:09:46
}

A navegação consulta e descarregamento dos títulos inseridos nas Bibliotecas Digitais UC Digitalis, UC Pombalina e UC Impactum, pressupõem a aceitação plena e sem reservas dos Termos e Condições de Uso destas Bibliotecas Digitais, disponíveis em https://digitalis.uc.pt/pt-pt/termos.

Conforme exposto nos referidos Termos e Condições de Uso, o descarregamento de títulos de acesso restrito requer uma licença válida de autorização devendo o utilizador aceder ao(s) documento(s) a partir de um endereço de IP da instituição detentora da supramencionada licença.

Ao utilizador é apenas permitido o descarregamento para uso pessoal, pelo que o emprego do(s) título(s) descarregado(s) para outro fim, designadamente comercial, carece de autorização do respetivo autor ou editor da obra.

Na medida em que todas as obras da UC Digitalis se encontram protegidas pelo Código do Direito de Autor e Direitos Conexos e demais legislação aplicável, toda a cópia, parcial ou total, deste documento, nos casos em que é legalmente admitida, deverá conter ou fazer-se acompanhar por este aviso.

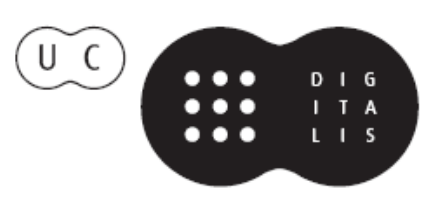




\section{Duarte Nuno Vieira Anthony Busuttil \\ Denis Cusack • Philip Beth}
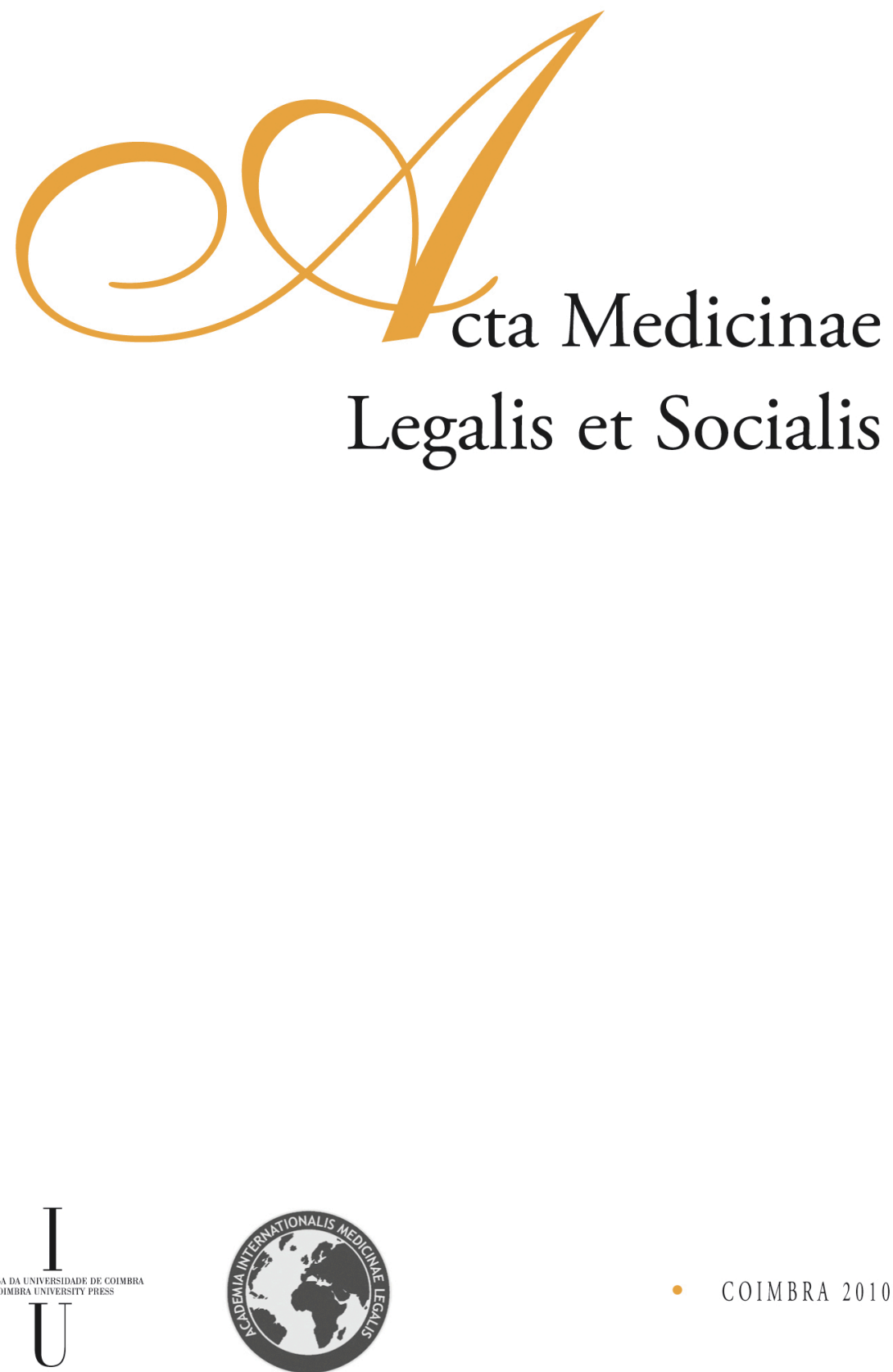


\title{
M. D. Freeman
}

Institute of Forensic Medicine, Faculty of Health Sciences, University of Aarhus, Denmark Dept. of Public Health and Preventive Medicine, Oregon Health and Science University School of Medicine, Portland, Oregon, USA

\section{A BAYESIAN ASSESSMENT OF UNEXPLAINED FRACTURE AS A FORENSIC TEST OF CHILD ABUSE; QUANTIFICATION OF UNCERTAINTY USING THE ERROR ODDS APPROACH}

\begin{abstract}
All forensic opinions can be characterized as probabilities, and all forensic methods upon which the probabilities are based can be described as tests of relevant evidence. Probability can also be described as a way to quantify uncertainty (as [1-probability] = uncertainty) and thus a means of assessing the validity of a forensic opinion. In the present paper a method of quantifying the uncertainty in forensic test results called the Error Odds is described. The Error Odds is a Bayesian metric that allows for calculation of the degree of uncertainty in a test result by using ordinary clinical terms and concepts. As an example of how the method can be easily applied to a common test result, the Error Odds calculation is used to quantify the uncertainty in the use of unexplained pediatric fracture as a test for child abuse. It is suggested that an Error Odds of 10:1 is the minimum threshold for the consideration of a single test result as evidence of guilt in a criminal proceeding.
\end{abstract}

\section{Introduction}

In February of 2009 the U.S. National Research Council of the National Academies released a report of a comprehensive analysis of deficiencies in the forensic sciences, including a list of 13 recommendations for the improvement of forensic science. 1 The third recommendation addressed the lack of research pertaining to accuracy, reliability, and validity in forensic sciences, and recommended the development of quantifiable measures of the uncertainty in the conclusion of forensic analyses. Uncertainty is quantified by probability, as the one is the complement of the other; i.e. [1-probability] $=$ uncertainty, and [1-uncertainty] = probability. 2

In a forensic setting, probability is used to quantify one's belief in the truth of a conclusion regarding the interpretation of evidence. One approach to probability is that of the Frequentist, in which many prior observations are used to predict a future event or an event with an unknown outcome. An example of this approach is the $17 \%$ probability that the roll of a die will result in a 6 , based on historical observations of many rolls of the die. In a forensic setting, such an approach would often be overly simplistic; for example, the prior observation that $81 \%$ of known offenders in the 
UK are men does not allow for the conclusion that it is more probable than not that an individual crime was committed by a man, particularly when there is evidence that a woman committed the crime. 3 In this example the probability that a crime was committed by a woman would be "conditioned" by the evidence, so that the probability more accurately reflects the known facts.

In the application of forensic medicine methods and tests to the investigation of a crime, where evidence may be present that modifies or conditions a probabilistic conclusion, a more accurate approach is that of the Bayesist, based upon the application of Bayes' Law. Simply stated, when applied in a forensic setting Bayes' Law tells us what we want to know given what we do know.4 Symbolically, Bayes' Law as applied to a positive test result can be depicted as $P(A \mid+$ test $)$; the probability that condition $A$ is truly present given a positive test result for condition A. In a forensic setting, Bayes' Law is what allows for the identification and avoidance of the Conditional Probability Fallacy, in which the erroneous assumption is made that the terms are reversible; that $P(A \mid+$ test $)=P(+$ test $\mid A) .5$ An example of the Conditional Probability Fallacy would be the incorrect conclusion that if $90 \%$ of Spaniards speak Spanish then it is equally true that $90 \%$ of Spanish speakers are from Spain. As applied to a forensic test, the Conditional Probability Fallacy occurs when it is assumed that the probability that a test will be positive when a condition is present is the same as the probability that a positive test means the condition is present.

\section{Error Odds}

A simple application of Bayes' Law for assessing the uncertainty in a forensic opinion that relies upon a positive test result is the Error Odds assessment (also known as a post-test probability in Bayesian terminology). The result of the Error Odds assessment is the ratio of true positive to false positive tests (also known as the likelihood ratio) given the expected "base rate" or prevalence of the condition of interest (also known as the pre-test probability). The Error Odds test can be illustrated with a theoretical drug test that has a $90 \%$ false positive rate (the same as the "sensitivity" of the test to the presence of drugs) and a $10 \%$ false positive rate (the rate at which the test misidentifies subjects with no drugs as positives, [1-specificity]) that is applied to two populations; one of felons and the other of factory workers. If we estimate, from a hypothetical epidemiologic study, a base rate of drug use among the felons of $90 \%$ and $10 \%$ among the workers, the Error Odds test gives a very clear assessment of the degree of uncertainty in a positive test result for both populations. This is illustrated in Figures 1 and 2.

Note that the result of the Error Odds assessment (OE) for the felons indicated that the drug test had a very high ratio (81:1) whereas the $\mathrm{OE}$ assessment for the same test applied to the factory workers demonstrated an equal probability of true and false positive (1:1). This example illustrates how the base rate is the most potent value in the OE calculation; while the ratio of base rate for the felons to the workers was 9:1 $(90 \%$ vs. $10 \%)$ the ratio of the OE result was the square of the base rate ratio; $81: 1$. Also note that the $\mathrm{OE}$ value is actually the odds against error; the rationale for this inversion is so that a positive test result with a low degree of uncertainty is always 
a whole number. As an illustrative example, the 81:1 Error Odds calculated for the drug test among felons would be 0.012 if the terms were inverted.

The Error Odds can also be calculated using the following formula:

$$
\mathrm{O}_{\mathrm{E}}=\frac{\text { true positive rate }}{\text { false positive rate }} \times \frac{\text { base rate }}{(1 \text {-base rate })}
$$

Using Bayesian terms this calculation would be described as the Likelihood Ratio multiplied times the Pre-test Odds, respectively. For the felons the calculation would be as follows:

$$
\mathrm{O}_{\mathrm{E} \text { felon }}=\frac{0.9}{0.1} \times \frac{0.9}{0.1}=81
$$

and for the workers it would be:

$$
\mathrm{O}_{\mathrm{E} \text { worker }}=\frac{0.9}{0.1} \times \frac{0.1}{0.9}=1
$$

\section{Methods}

In the present investigation we describe the application of the Error Odds assessment of test validity to the use of unexplained fracture as a proxy for child abuse among infants and toddlers. Skeletal fractures have been described in as many as $1 / 3$ of cases of suspected abuse. 6 Because the fractures are often occult, not correlated with a first-person account of injury, and occur in a particularly vulnerable population, the presence of unexplained fracture is sometimes interpreted as a reliable indication of intentional violence, despite the fact that most pediatric fractures are the result of unintentional trauma.7 Additionally, some children are more susceptible to fracture because of metabolic and other conditions that affect skeletal integrity. 8

Intentional violence against infants and toddlers is far from rare, and cases of confirmed child abuse with fracture will most often have collateral evidence of abuse. In the case in which unexplained skeletal fracture is present in an infant or toddler and there is no supporting evidence that the cause of the fracture was abuse a quandary arises; is unexplained fracture a valid and reliable proxy for child abuse?

In order to perform an Error Odds assessment of fracture as a test for abuse the three unique elements of the calculation must be identified and estimated (true and false positive rate and base rate). When a test is used as a proxy for a specific condition, meaning, for these circumstances, that when an unexplained fracture is present that there is always abuse, the true positive rate for the test is $100 \%$. Use of the test as a proxy also means that the test does not have the ability to correctly identify cases in which a fracture did not result from abuse, and thus the test has a $100 \%$ false positive rate as well.

The determination of a base rate to complete the Error Odds calculation can be derived from the literature. The most comprehensive publication on the base rate of abuse among children with fracture is the work of Kemp and colleagues.9 In their systematic comprehensive review of the medical literature these authors identified 32 out of 439 reviewed studies that allowed for the meta-analysis of abuse rates for fractures to various parts of the body. The authors found that the site of fracture with the highest probability of abuse was the ribs $(71 \%$, with a $95 \%$ confidence interval 
of $42-91 \%$ ), and next was the humerus (54\%, CI 20-88\%), the skull (30\%, CI 19$46 \%)$, and then the femur (28\%, CI 14-44\%). Based upon their results Kemp et al. concluded that no single fracture should be used as a test for abuse, although they did not describe a threshold value that would make such a test acceptable as evidence of abuse.

\section{Results}

Using the values reported by Kemp et al. an Error Odds estimate of the validity of skeletal fracture as a proxy for child abuse can be calculated. Since the true positive rate and false positive rate are both $100 \%$ they cancel out in the OE calculation (making the likelihood ratio 1), and therefore the Error Odds is arrived at quite simply by dividing the base rate of abuse by [1- base rate] of abuse. The range of OE values for unexplained fracture as a proxy for abuse is presented in Table 1.

\section{Discussion}

It has been previously suggested that a minimal threshold value to consider the use of test results as evidence in a criminal matter is a post-test probability or Error Odds of 10:1, as this is approximately equal to a $90 \%$ confidence interval.10 By this standard only the extreme upper end of the confidence interval for rib fractures would meet the criteria $(\mathrm{OE}=10.1)$, and the majority of the probable values are below the minimal value for consideration.

Prior authors have described a high rate of metaphyseal fracture amongst pediatric victims of homicidal abuse, and this finding has been misinterpreted by some as evidence that there is an equally high probability that abuse is the cause of such fractures when they are discovered.11 As described earlier in this paper, this misconstruction is a Condition Probability Fallacy, in which the mistaken conclusion is drawn that $P($ Abuse $\mid$ Fracture $)=P($ Fracture $\mid$ Abuse $)$. With no information on the base rate of abuse among children with metaphyseal fracture the presence of such fractures can only be considered as important but incomplete evidence of intentional violence.

\section{Conclusions}

In keeping with the NAS recommendations on the forensic sciences, we have described a method of assessing the uncertainty inherent in a forensic test for child abuse that relies solely upon the presence of an unexplained fracture. The Error Odds application of Bayes' Law is a simple method of uncertainty quantification that uses common clinical rather than Bayesian language to describe the terms in the calculation. This approach provides an easily understood metric for assessment of the relative weight that forensic specialists and fact finders can give to individual test results.

It is apparent from the results of the Error Odds assessment presented herein that the degree of uncertainty inherent in the use of unexplained fracture as test for child 
abuse indicates that it is not reliable for this purpose when additional evidence of abuse is not present.

\section{Acknowledgement}

The author gratefully acknowledges the editorial input of Prof. Doug Mossman in the preparation of this manuscript.

\section{References}

1 Strengthening Forensic Science in the United States: A Path Forward. http://www.nap.edu/ catalog/12589.html (accessed 6-20-09).

2 Dawid A P, Mortera J. Forensic identification with imperfect evidence. Biometrika 1998;85;83549. (Correction: Biometrika 1999;86: 974.).

$3 \mathrm{http}: / /$ www.crimeinfo.org.uk/servlet/factsheetservlet?command=viewfactsheet\&factsheetid= 110\&category=factsheets (accessed 6-12-07).

4 Leung WC. The prosecutor's fallacy--a pitfall in interpreting probabilities in forensic evidence. Med Sci Law. 2002 Jan;42(1):44-50.

5 Paulos JA. Innumeracy: Mathematical Illiteracy and its Consequences 1988 New York : Hill and Wang; ISBN 0809074478.

6 Belfer RA, Klein BL, Orr L. Use of the skeletal survey in the evaluation of child maltreatment. Am J Emerg Med 2001;19:122-4.

7 Rennie L, Court-Brown CM, Mok JY, Beattie TF. The epidemiology of fractures in children. Injury 2007;38:913-22.

8 Bishop N, Sprigg A, Dalton A. Unexplained fractures in infancy: looking for fragile bones. Arch Dis Child 2007;92:251-6.

9 Kemp AM, Dunstan F, Harrison S, Morris S, Mann M, Rolfe K, Datta S, Thomas DP, Sibert JR, Maguire S. Patterns of skeletal fractures in child abuse: systematic review. BMJ 2008 Oct 2;337:a1518. doi: 10.1136/bmj.a1518.

10 Freeman MD, Hand ML, Rossignol AM. Applied Forensic Epidemiology: A Bayesian evaluation of forensic evidence in a vehicular homicide investigation. J Forensic Legal Med 2009 Feb;16(2):83-92. Epub 2008 Oct 21.

11 Kleinman PK, Marks SC Jr. A regional approach to classic metaphyseal lesions in abused infants: the distal tibia. AJR Am J Roentgenol. 1996 May;166(5):1207-12.

\begin{tabular}{|c|c|c|c|}
\hline Fracture site & Confidence Interval & $\begin{array}{c}\text { Base rate/ [1-b ase } \\
\text { rate] range }\end{array}$ & $\begin{array}{c}\text { Error Odds } \\
\text { range }\end{array}$ \\
\hline Rib & $0.42-0.91$ & $0.42 / 0.58,0.91 / 0.09$ & $0.72-10.1$ \\
\hline Humerus & $0.20-0.88$ & $0.20 / 0.80,0.88 / 0.12$ & $0.25-7.3$ \\
\hline Skull & $0.19-0.46$ & $0.19 / 0.81,0.46 / 0.54$ & $0.23-0.85$ \\
\hline Femur & $0.14-0.44$ & $0.14 / 0.84,0.44 / 0.56$ & $0.17-0.79$ \\
\hline
\end{tabular}

Table 1 


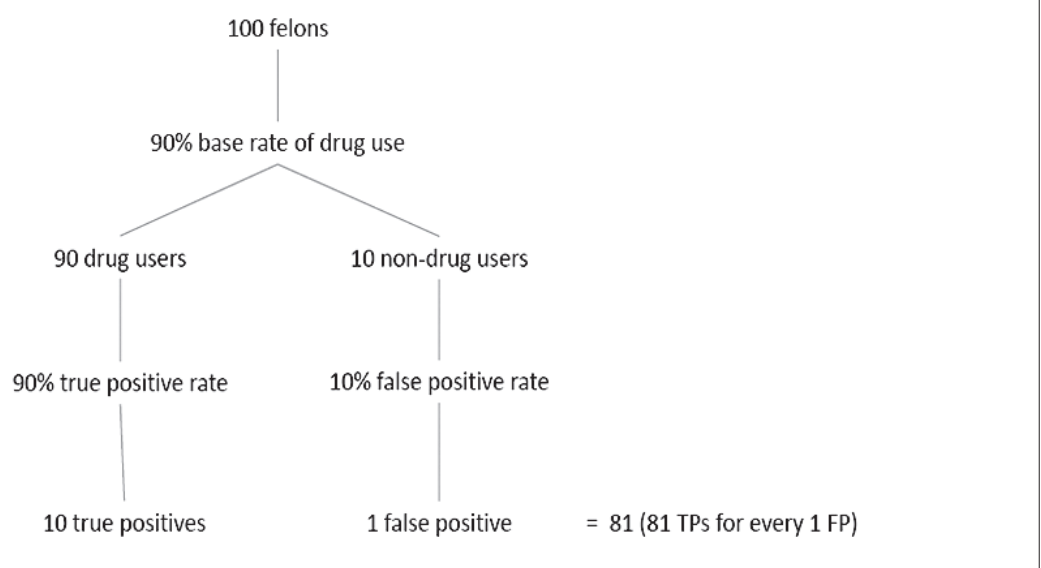

Figure 1 - Error Odds assessment of drug testing of felons

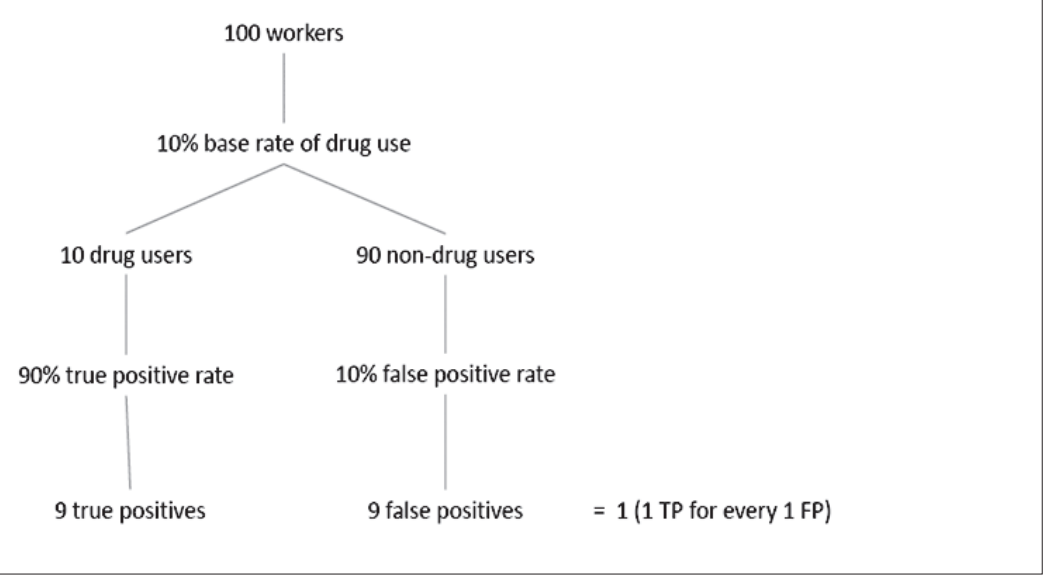

Figure 2 - Error Odds assessment of drug testing of workers 